\title{
O Mapa do Feminicídio na Polícia Civil do Piauí: UMA ANÁlise Organizacional-SistÊMICA
}

\author{
Eugênia Nogueira do Rêgo Monteiro Villa* \\ Bruno Amaral Machado**
}

\begin{abstract}
1 Introdução. 2 O percurso metodológico. 3 O mapa do feminicídio. 4 As lacunas hermenêuticas e operacionais do feminicídio. $5 \mathrm{O}$ discurso policial do feminicídio. 5.1 O espaço policial. 5.1.1 Rotinas cognitivas na categorização do feminicídio. 5.1.1.1 As decisões periciais. 5.1.1.1.1 Laudo de exame pericial cadavérico. 5.1.1.1.2 Laudo de exame pericial em local de crime 5.1.1.2 As decisões da polícia judiciária. 6 Programa operacional na perspectiva de gênero. 7 Considerações finais. Referências.
\end{abstract}

\section{RESUMO}

O estudo insere-se no campo da violência contra a mulher, na perspectiva do assassinato de mulheres por razões de gênero. A partir de inferências extraídas de bancos de dados oficiais da Polícia Civil do Piauí e análise de inquéritos policiais que apuraram feminicídio, elabora-se um mapa do feminicídio no Estado do Piauí, tomando-se por base as mesmas categorias eleitas por Waiselfisz no Mapa da Violência 2015 - Homicídio de mulheres no Brasil como paradigma de análise dos dados. A pesquisa é pioneira porque constitui o primeiro mapa após a vigência da Lei $\mathrm{n}^{\mathrm{O}}$. 13.104/15 que instituiu o feminicídio no Brasil. O estudo detecta lacunas no tipo penal que dificultam a aplicação da qualificadora feminicídio sobre o que se poderia entender por matar uma mulher "por razões da condição do sexo feminino". Para compreender como essa lacuna vem sendo superada no âmbito da cultura organizacional policial, o estudo analisa o conteúdo de 27 de um total de 50 inquéritos policiais de feminicídios consumados produzidos no período de 10. 3.15 a 30. 8.16. Foram eleitos como objeto de análise: laudos periciais, termos de oitivas, auto de prisão em flagrante delito, interrogatório e relatório. Em seguida, a pesquisa, orientada pela análise do discurso e pela abordagem organizacional, mapeia categorias empíricas neles presentes para adentrar na rotina policial e verificar como as organizações observam o feminicídio e de que modo se comunicam (decidem).

Palavras-chave: Linguagem do Feminicídio. Sistemas. Metodologia investigatória. Organizações policiais.

* Doutoranda do Programa de Doutorado em Direito e Políticas Públicas do Centro Universitário de Brasília (UNICEUB). Mestre em Direito pela UNISINOS/RS. Delegada de Polícia Civil do Estado do Piauí. Diretora de Gestão Interna da SSP/PI. Professora do Curso de Direito da UESPI e UNINOVAFAPI. E-mail: <eugenianogueiravilla@yahoo.com.br>.

** Professor do Programa de Mestrado e Doutorado em Direito e Políticas Públicas do Uniceub. Doutor em Direito (especialidade Sociologia Jurídico-penal pela Universidade de Barcelona). Pós-doutorado em Sociologia (UnB - Jonh Jay). Promotor de Justiça (MPDFT). Agradecemos os comentários de Ana Luisa Rivera, Antonio Suxberger e Amon Albernaz. E-mail: <brunoamachado@hotmail.com>. 


\section{INTRODUÇÃO}

O assassinato de mulheres por razões de gênero é considerado, em muitos países, um problema social, impulsionando a adoção de estratégias biopolíticas (LAGE; NADER, 2013, p. 286). O Brasil, segundo o Mapa da Violência 2015 - Homicídio de mulheres no Brasil, ocupa o $5^{\circ}$ lugar no ranking de 83 países nos assassinatos de mulheres, com taxa de 4,8 homicídios por 100 mil mulheres. No Piauí, a série histórica de 2003 a 2013 do mesmo estudo registrou 399 assassinatos de mulheres - 36/ano ou 0,099/dia - 14 lugar no ranking da taxa de assassinatos de mulheres dos estados (WAISELFISZ, 2015, p. 27).

Dados estatísticos produzidos pelo Núcleo de Estatística e Análise Criminal, em parceria com o Núcleo de Estudo e Pesquisa em Violência de Gênero, da Secretaria de Segurança Pública do Piauí, apontam que, no período de 10 de março de 2015 (data da vigência da Lei do Feminicídio) até 30 de agosto de 2016 (período histórico da estatística oficial), foram registrados 84 (oitenta e quatro) casos de crimes violentos letais intencionais - CVLI femininos. Dos 84 casos, 50 deles foram tipificados como feminicídio.

Os autores eram, na maioria dos casos, conhecidos pelas vítimas, e a ação se dera em suas casas e nos momentos de descanso familiar, fatores que podem estar intrinsecamente ligados a uma cultura patriarcal orientada pelo poder masculino desde a era colonial brasileira, cujo Código Filipino, vigente à época, permitia que o marido assassinasse a esposa adúltera ou a enclausurasse, além das filhas (LAGE; NADER, 2013, p. 287).

A discussão jurídica no Brasil sobre o assassinato de mulheres na perspectiva de gênero ocorre a partir da vigência da Lei no $.13 .104 / 15$ (BRASIL, 2015a), que inseriu a qualificadora feminicídio no art.121 do Código Penal (BRASIL, 2015b). O tema, por ser atual na comunidade jurídica, apresenta lacunas nos planos da legislação e conta com escassa produção teórica, não se identificando ainda inferências ou metodologias de interpretação específicas que auxiliem as organizações que participam da divisão do trabalho jurídico-penal na compreensão dos contextos em que são praticados os atos de feminicídio.

Uma metodologia investigatória na perspectiva de gênero, que leve em conta as decisões organizacionais da polícia, poderá contribuir para a construção de protocolos que auxiliem as investigações dos feminicídios, qualificando a aplicação do direito penal à realidade empírica, além de favorecer o debate, o planejamento e a efetividade dos direitos das mulheres em situação de violência na perspectiva de gênero.

Sob a ótica formal, pretende-se discutir o feminicídio, na perspectiva de gênero, a partir do termo "condição do sexo feminino", elemento caracterizador da sua prática (Lei n . 13.104, de 10 de março de 2015) (BRASIL, 2015a). No plano material, propõe-se verificar, na perspectiva organizacional, como o feminicídio é operado nas decisões policiais, ou seja, como vem sendo compreendido pela polícia, o que supõe contemplar a divisão do trabalho jurídico-penal e, especificamente, da Polícia Civil, no desempenho das suas distintas funções de polícia judiciária e de polícia técnico-científica.

As relações de gênero demarcam o território da expressão "condição do sexo 
feminino" ou sobre o que se poderia compreender de que forma o "feminino" figura como "condição" para qualificar um assassinato. A pesquisa pretende contemplar os discursos jurídicos e organizacionais, bem como captar as falas dos personagens envolvidos no plano fático e os discursos da organização policial (FOUCAULT, 2013, p. 62). Sob o enfoque sistêmico, a discussão também sugere parâmetros hermenêuticos. A argumentação jurídica supõe distinções balizadas por critérios de validez e orientadas pelos códigos do sistema jurídico (direito/ não direito), bem como outras distinções relevantes, particularmente associadas às informações já registradas no sistema (redundância) e aquelas originadas do entorno (variações), como a autorreferência/ heterorreferência (LUHMANN, 2016, p. 524-525). As relações de gênero, evidenciadas nos discursos selecionados para análise, são relevantes para a releitura dos programas condicionais do direito.

Em outros estudos, sustentamos que a abordagem organizacional-sistêmica propicia ferramentas para análise das organizações que participam da divisão do trabalho jurídico-penal. Compreender os processos decisórios das organizações supõe investigar extenso rol de premissas decisórias. Distinguem-se, assim, os programas condicionais (definidos pelos tratados, legislações e atos normativos), dos programas finalísticos, como as prioridades organizacionais estabelecidas, os planos estratégicos, etc. O organograma interno, conformado pela distribuição de atribuições e hierarquia interna e as formas de recrutamento de membros também se constituem em premissas decisórias. A cultura organizacional, consistente nas rotinas cognitivas que orientam as decisões, também é relevante para mapear a forma como decidem (comunicam) as organizações (MACHADO, 2014, p. 36-42). No campo organizacional, este artigo pretende mapear a programação organizacional (normativa e atos administrativos) que estabelece o roteiro para as decisões das referidas unidades da Polícia Civil do Piauí: polícia investigatória e polícia técnico-científica, partícipes da divisão do trabalho policial investigatório do feminicídio (indiciamentos, relatórios, autos de prisão em flagrante e representações por medidas cautelares), a fim de discutir se o modelo organizacional é adequado para a condução das investigações do feminicídio.

\section{O PERCURSO METODOLÓGICO}

A SSP/PI criou, em 2 de março de 2015, o Núcleo Policial Investigativo do Feminicídio, com competência para investigação do Feminicídio em todo o estado. $\mathrm{O}$ ato que instituiu a estratégia o conceituou "[...] como sendo o assassinato de meninas, mulheres, travestis e mulheres transexuais baseado em relações de gênero." (PIAUÍ, 2015, p. 3).

Dedicado exclusivamente ao feminicídio, o Núcleo demandou metodologia policial investigatória que privilegiasse a perspectiva de gênero, uma vez que a metodologia tradicional aplicada aos assassinatos de mulheres se baseava nas mesmas categorias dos 
homicídios em geral. Em abril de 2016, o Piauí adotou as Diretrizes nacionais feminicídio - investigar, processar e julgar (BRASIL, 2016) com perspectiva de gênero as mortes violentas de mulheres propostas pela SENASP em parceria com a ONU MULHERES e a Secretaria de Política para Mulheres da Presidência da República.

Aliada à metodologia investigatória, desenvolveu-se estatísticas criminais com recorte de gênero para assinalar um diferencial no assassinato de mulheres em face dos demais CVLI.

A pesquisa, inicialmente, procurou identificar o número de mulheres assassinadas no Piauí no período de 10 de março de 2015 (data da vigência da Lei do Feminicídio) até 30 de agosto de 2016 (período histórico da estatística oficial), tendo sido apurados 84 (oitenta e quatro) casos de CVLI femininos. Uma vez definida a quantidade de assassinatos de mulheres no período, passou-se ao levantamento dos seus registros nos bancos de dados da Polícia Civil em três sistemas de informação: Sistema de Monitoramento de Crimes Violentos Letais Intencionais (SIMCVLI), Sistema de Procedimentos Policiais (SISPROCEP) e Sistema de Boletim de Ocorrência (SISBO), além da verificação dos inquéritos policiais a eles referentes e relatos dos(as) Delegados(as) que presidiram as investigações.

O estudo dos casos de feminicídio foi primeiro direcionado à elaboração do Mapa do Feminicídio, analisando-se dados oficiais da Polícia Civil (PC-PI), e depois aos discursos e aos documentos oficiais que consubstanciam as decisões (forma de comunicação das organizações) constantes de inquéritos policiais. Verificou-se que, dos 84 registros de CVLI femininos, 50 foram tipificados como feminicídio, de modo que o Mapa do Feminicídio foi elaborado com base nos dados dos 50 feminicídios. Em seguida, a pesquisa voltou-se à análise de 27 casos do total de 50 identificados no Estado. Nesse momento, não foi possível a abrangência da totalidade, uma vez que os demais ( 23 casos) estão dispersos por delegacias do interior. A amostra correspondeu, portanto, a 54\% dos casos ou 27 feminicídios consumados.

\section{O MAPA DO FEMINICÍDIO}

O mapeamento do feminicídio tomou por base consultas aos Sistemas SIMCVLI, SISPROCEP, acervo das segundas vias dos IPL do Núcleo de Estudo e Pesquisa em Violência de Gênero SSP/PI e consulta aos(às) Delegados(as) que presidiram os Inquéritos Policiais de Feminicídio.

As inferências extraídas dos sistemas de informação da PC-PI, a pesquisa realizada por Waiselfisz (2015), sobre o homicídio de mulheres no Brasil, no período de 2003 a 2013, assim como a pesquisa feita pelo Analista Criminal da SSP/PI (AGUIAR, 2016) possibilitaram a definição de categorias de análise na perspectiva das mulheres assassinadas: cor das vítimas, idade, meios utilizados e locais das agressões. 
A pesquisa apurou que mais da metade dos assassinatos de mulheres foram tipificados como feminicídio $(59,52 \%)$, com prevalência no interior do estado ( $80 \%$ deles). Porém, em análise dos municípios, Teresina ocupa o primeiro lugar no ranking dos 224 municípios piauienses com 10 casos. Todos os feminicídios pesquisados tiveram como vítimas mulheres, não tendo sido registrado nenhum caso contra pessoas transgênero.

Definida a amostra da pesquisa, passou-se a analisar o perfil das mulheres assassinadas, considerando-se as categorias selecionadas pelo Mapa da Violência 2015 e outras categorias possíveis de serem catalogadas a partir das consultas aos bancos de dados da polícia. A primeira delas diz respeito à cor da pele das vítimas com base nas declarações dos laudos de exames periciais cadavéricos, ou seja, tomara-se por base o discurso policial oficial constante dos laudos periciais expedidos pelo Instituto Médico Legal (IML) e registrados no SIMCVLI. Saliente-se que os parâmetros adotados pelos Médicos Legistas não observam quaisquer critérios formais de classificação por cor de pele, mas tão somente a percepção pessoal do legista.

A categoria Negra (parda e preta) prevaleceu, correspondendo a 37 vítimas de um total de 50, ou 74\%. Quanto à idade da vítima, apurou-se que metade das mulheres assassinadas estava na faixa etária de 30 a 59 anos, ou seja, as mulheres adultas são aparentemente as mais vulneráveis, seguidas daquelas que se posicionam na faixa etária de 18 a 29 anos (24\%). O indicador foi construído a partir da metodologia adotada pelo Mapa da Violência 2015, que agrupara as idades a partir de definições legais e ciclos de vida.

O dado piauiense também contraria a pesquisa de Waiselfisz (2015), cuja faixa mais vulnerável se dá entre 18 a 29 anos. Ainda com relação à vítima, apurou-se a prevalência de mulheres solteiras. Porém, em razão de muitas lacunas nos sistemas de informação utilizados, não foi possível aferir esse dado. Pode-se inferir quanto ao perfil das vítimas que as mulheres mais vulneráveis se encontram na fase adulta, são pardas e solteiras. Quanto aos elementos fáticos, a arma branca do tipo faca foi o meio utilizado na metade dos casos de feminicídio.

Na perspectiva do local de crime, o estudo apurou que 19 dos 50 feminicídios do Piauí ocorreram na residência da vítima (38\%). Contudo, como há a prevalência do local por definir (48\%), não se pode afirmar com exatidão a majoritária natureza do local dos feminicídios porque os dados carecem da exata qualificação.

Os dados também revelam que, em mais da metade dos casos (58\%) ou 29 deles, o agressor é conhecido da vítima, tendo mantido com ele relações de confiança com base na afetividade e/ou familiar. Inferiu-se que a relação entre o vínculo e o local do assassinato sugere cenários de vulnerabilidade em face da vítima, visto que 17 das 29 vítimas (63\%) que possuíam vínculo afetivo ou familiar com o agressor foram assassinadas em suas residências, ou seja, o risco da vítima de ser assassinada em sua casa é prevalente, sobretudo quando se trata de vínculos familiares. 


\section{AS LACUNAS HERMENÊUTICAS E OPERACIONAIS DO FEMINICÍDIO}

O recente tipo penal inserto no Código Penal brasileiro pela Lei $\mathrm{n}^{\circ} .13 .104$, de 10 de março de 2015 (BRASIL, 2015a), previsto nos $\S \S 2^{\circ}$ e $2^{\circ}$ - A do inciso VI do art. 121, apresenta lacunas que instigam o estudo a indagar o que se pode entender por matar uma mulher "por razões da condição do sexo feminino." O texto remete a duas situações legais: âmbito doméstico e familiar e menosprezo ou discriminação à condição de mulher. A lei impôs desafios às organizações responsáveis pela investigação, processamento e julgamento dos casos de feminicídio, no caso, Polícia, Ministério Público e Judiciário. Como o feminicídio é crime doloso contra a vida, o desafio torna-se ainda maior porque o julgamento do que vem a ser "condição do sexo feminino" cabe ao Conselho de Sentença, formado por pessoas do povo que julgarão conforme suas consciências e convicções pessoais.

A categorização sugere cuidado ao observar os espaços de decisão, bem como a construção de metodologias ou protocolos que pretendem uniformizar os processos decisórios. Sob o enfoque sistêmico, ganha especial relevância as abordagens teóricas que investem na reconstrução e nas ressignificações dos conceitos jurídicos a partir da abertura cognitiva ao entorno, juridicamente inteligíveis pelo argumento heterorreferente. $O$ debate remete à diferenciação interna do sistema jurídico e sugere novas descrições, suficientemente complexas para repensar a igualdade (LUHMANN, 2016, p. 678-680).

A discussão sobre o que consiste "a condição do sexo feminino" ou "condição de mulher" interpela recentes análises sobre o reconhecimento e a precariedade. Butler vincula a precariedade à noção "[...] política de 'condição precária' [...], condição de violável, marca comum a toda e qualquer vida [...]", ou "[...] condição de ser reconhecido". Para ela, "[...] há 'vidas' que dificilmente [...] são reconhecidas como vidas"; e indaga: "Em que sentido, então, a vida excede sempre as condições normativas de sua condição de ser reconhecida"? (BUTLER, 2015, p. 16-17). Nesse sentido: "O ser do corpo [...] é um ser que está sempre entregue a outros, a normas, a organizações sociais e políticas que se desenvolveram historicamente a fim de maximizar a precariedade para alguns e minimizar a precariedade para outros." (BUTLER, 2015, p. 15). Em um esforço de interpretação, sugere-se que a 'condição de ser mulher' ou a 'condição do sexo feminino' que caracterizam o feminicídio modelam determinado sujeito a ser reconhecido como merecedor da aplicação da norma.

Porém, indaga-se qual seria o 'molde' ou o 'marco' a ser considerado para o reconhecimento do sujeito 'mulher' e/ou do sujeito 'feminino' que torne possível a aplicação da norma? Haveria um padrão universal? A discussão aproxima-se do debate contemporâneo sobre a universalidade do direito e seus efeitos para a compreensão dos programas condicionais do sistema jurídico. Ao discutir o conceito, critica Butler o intento de definir categoria abstrata de universalidade e evidencia particular tensão com os particularismos. Assim:

O que é universal é, portanto, o que pertence a todas as pessoas, mas não é tudo o que pertence a cada pessoa. Na realidade, se pudermos dizer que as concepções, os estados de consciência, os sentimentos, o que é específico e vital, 
também pertencem a todas as pessoas, temos identificado aparentemente uma característica universal que não debaixo da rubrica de universalidade. Deste modo, o requerimento abstrato da universalidade produz uma situação na qual a universalidade mesma se duplica: na primeira instância é abstrata e na segunda é concreta (BUTLER; LACLAU; ZIZEK, 2000, p. 29).

A vacuidade do discurso legal do feminicídio conduz à construção de uma "[...] universalidade pela exclusão da particularidade no universal. Não há como incluir a particularidade no universal sem que primeiro se negue a essa particularidade. A universalidade não procede sem destruir aquilo que tenta incluir [...]." (BUTLER; LACLAU; ZIZEK, 2000, p. 30). O termo "condição do sexo feminino" fortalece a ideia de diferença entre seres humanos, tomando-se por base o sexo biológico pautado nas genitálias, que, estabelecendo oposições, conduz a um substrato de dominação, no caso, do sexo masculino. Esse ponto de oposição, argumenta Butler, seria ele mesmo "[...] o instrumento através do qual opera a dominação, e que sem querer, temos fortalecido os poderes de dominação através de nossa participação na tarefa de nos opormos." (BUTLER; LACLAU; ZIZEK, 2000, p. 34). Noutras palavras, sendo a lei uma espécie de resistência, poderá ela mesma se constituir no instrumento dissimulado da dominação.

O termo "condição do sexo feminino" corresponderia ao que Hegel denomina por um "[...] ponto vazio do eu (self) absolutamente livre, a mais fria e mesquinha de todas as mortes, não mais significativo que cortar um repolho ou beber água." Pode-se, com inspiração no pensamento hegeliano entrever, no discurso legal, que as mulheres "[...] passam a constituir nulidades cujo único ato é anular o mundo que os haja anulado." (BUTLER; LACLAU; ZIZEK, 2000, p. 37). A tarefa, portanto, de se transcender a universalidade para se alcançar a particularidade seria a de considerar, conforme pondera Laclau:

[...] que cada identidade particular nunca está completa em seu esforço por obter a autodeterminação. Uma identidade particular é entendida como atada a um conteúdo específico como gênero, raça ou etnia. $O$ traço estrutural que se supõe que todas essas identidades compartem é uma incompletude constitutiva (BUTLER; LACLAU; ZIZEK, 2000, p. 37).

Pode-se indagar como e de que forma se poderia alcançar a individualidade estabelecendo condições de reprodutibilidade? Ou então, "[...] o que poderia ser feito para mudar os próprios termos da condição de ser reconhecido a fim de produzir resultados mais radicalmente democráticos?" (BUTLER, 2015, p. 20). A autora pondera: "[...] da mesma forma que as normas da condição de ser reconhecido preparam o caminho para o reconhecimento, os esquemas de inteligibilidade condicionam e produzem essas normas." (BUTLER, 2015, p. 21, grifo nosso). O sujeito mulher não pode ser constituído ontologicamente, mas enquadrado (to be framed) de acordo com o universo que se elegeu para emoldurá-lo. Porém, o campo emoldurado constitui um cenário que poderá ser ampliado ou reduzido pelo sujeito que o emoldura. Em outras palavras, "enquadrar o enquadramento" para verificar quais categorias são consideradas no ato de emolduramento. Entender a moldura como elemento que extravasa o cenário eleito, segundo Butler, é o que permite a descoberta de novos cenários, 
"[...] o que significa que "o enquadramento" não é capaz de conter completamente o que transmite, e se rompe toda vez que tenta dar uma organização definitiva a seu conteúdo.” (BUTLER, 2015, p. 26). Haveria, assim, uma espécie de fissura na moldura que possibilita ultrapassar mecanismos de controle estabelecidos. Pode-se inferir que o termo "condição do sexo feminino" remete a campo que se abre a permanentes rupturas na moldura, porque demanda o reconhecimento de novos e múltiplos contextos fincados na realidade empírica vivenciada por cada sujeito em particular.

O debate teórico não se esgota nessas questões. Os significados da prática também devem ser interpretados em perspectiva que supera a mera análise das motivações dos agentes. Há que se indagar além das ações racionais, orientadas a partir de estruturas de gênero. Assim, interpreta Segato: "[...] hay un gesto de más, una marca de más, um rasgo que excede su finalidad racional [...]", podendo dizer-se "[...] que se trata de una violencia instrumental orientada hacia un valor, esto es, la reparación o adquisición de un prestigio" (SEGATO, 2010, p. 42-44). A categoria gênero nem sempre é explícita e evidente, o que dificulta muitas vezes a atividade hermenêutica, "[...] pues se trata de una estructura de relaciones y, como tal, tiene un carácter eminentemente abstracto, que se reviste de significantes perceptibles, pero que no se reduce ni se fija a éstos." (SEGATO, 2010, p. 67). Na lente da antropóloga argentina, desenha-se um "masculino invisível", ao mesmo tempo abstrato e estável, que atua como "[...] soporte ideológico que sustenta la jerarquía de prestigio de las tareas y la estructura [...] patriarcales”. A tradução à linguagem jurídica e aos sistemas organizacionais supõe levar em conta que "[...] que el patriarcado es simbólico y sus huellas solo pueden ser identificadas mediante uma "escucha" adecuada y advertida" (SEGATO, 2010, p. 70). Nesse cenário, "[...] Nuestra política [...] debe dirigirse a develar los procesos de tránsito y de circulación que ocurren constantemente, pero permanecen ocultos por el peso de las representaciones que prescriben y presionan para reproducir la adhesión de los sujetos a posiciones establecidas como determinantes y originarias." (SEGATO, 2010, 74). ${ }^{1}$

O tema remete a questões teóricas importantes para o direito. A tarefa certamente supõe adensar a argumentação dogmático-penal em pontos centrais da teoria do delito: a teoria subjetiva do tipo e a culpabilidade. A discussão remete ao debate do século XIX entre determinismo e livre arbítrio (Positivismo Criminológico X Escola Clássica). A construção de critérios racionais, tanto objetivos quanto subjetivos, para imputação da responsabilidade penal conformou repertório de categorias acionadas como balizas para a intervenção penal. Recentemente, o tema foi objeto de reflexões entre os penalistas, confrontados com as perturbações trazidas pelos últimos estudos da neurociência. Ao se colocar em questão a liberdade daquele que pratica ações violentas, a dogmática penal foi interpelada a produzir novas descrições a dar inteligibilidade e traduzi-las em informações operáveis pelo subsistema jurídico-penal. Um dos cenários que se desenha é a ressignificação da categoria liberdade a partir de parâmetros jurídicos, e não naturalísticos, que contemplem as relações intersubjetivas fundadas em marcos de sociabilidade historicamente delimitadas (SÁNCHEZ, 2011, p. 45-46). 
A discussão não é alheia ao debate sobre o feminicídio. Ao trazer a variável estrutural como vetor hermenêutico da prática, a análise supõe ir além da subjetividade (motivações por sentimentos ou emoções) e repercute na prática do direito. Se considerado o feminicídio como qualificadora objetiva, apresenta-se como compatível com qualificadoras subjetivas como o motivo fútil ou torpe. O tema certamente requer a produção de novos artefatos teóricos que permitam rediscutir categorias penais (redundância) a partir das variações trazidas ao debate (LUHMANN, 2016, p. 524-525). Em términos sistêmicos, conjetura novas autodescrições do subsistema jurídico-penal, orientadas pela distinção autorreferências (categorias dogmático-penais estabilizadas, como a teoria subjetiva do tipo e a culpabilidade) heterreferências (estrutura de gênero). $O$ tema é certamente complexo e presume abordagem que ultrapassa o objetivo central deste artigo. Pretende-se, neste momento, a partir da análise dos casos de feminicídio selecionados neste estudo, interpelar a realidade empírica das mulheres assassinadas em face da cobertura legal idealizada. O esforço para preencher a lacuna teórica do feminicídio no plano jurídico supõe observar, também, a realidade empírica das organizações responsáveis pela investigação dos casos de feminicídio, a fim de compreender como a vacuidade opera no âmbito das premissas que orientam as decisões (forma de comunicação organizacional), particularmente da cultura organizacional policial. $O$ estudo pretende voltar-se à atividade investigatória policial, primeira fase da persecução penal, a fim de verificar como a polícia vem descrevendo os limites do feminicídio.

\section{O DISCURSO POLICIAL DO FEMINICÍDIO}

Descrito o cenário do feminicídio no Piauí no período considerado, passamos a analisar as decisões organizacionais da polícia no âmbito dos respectivos inquéritos policiais (IPL) a partir de alguns questionamentos: Como a polícia observa a categoria feminicídio? De que forma é ela operacionalizada? Pode-se inferir que existem limites cognitivos a serem considerados na capitulação do feminicídio no sistema policial? O sistema operativo da polícia abre-se cognitivamente ao entorno?

\subsection{O ESPAÇO POLICIAL}

Inicialmente, é preciso assinalar que a atividade policial é desempenhada por sujeitos que "[...] interpretam determinadas regras e «criam» outras para regular suas ações." (MACHADO, 2014, p. 26). O sistema policial orienta-se por rotinas cognitivas e doutrinas específicas voltadas à padronização das investigações criminais. Caracteriza-se como espaço dotado de regularidade e sistematicidade de ações que culminam nos processos decisórios a cargo de seus agentes, especialmente, na hierarquia policial, delegados e peritos.

A metodologia a ser empregada na investigação não tendo sido disciplinado em lei fez que "esse espaço não regulamentado gera zonas de incerteza que produzem es- 
quemas organizativos não oficiais [...].” (MACHADO, 2014, p. 26), ou seja, há espaço de discricionariedade a ser preenchido pelas decisões na condução do IPL. O espaço de discricionariedade não raramente é povoado por mitos organizacionais. A racionalidade que distingue a atuação policial se apresenta como atividade especializada e, portanto, controlada por grupo específico, reconhecido como instituição que opera a partir de rotinas próprias e relevantes socialmente. ${ }^{2}$

\subsubsection{Rotinas cognitivas na categorização do feminicídio}

Sob a perspectiva organizacional, a pesquisa dirige o foco para o conteúdo dos IPLS que compõem a amostra, a fim de verificar como operam os processos decisórios, bem como eventuais interações das unidades policiais na investigação do feminicídio, no caso específico, o Instituto de Medicina Legal (IML), a Perícia Técnico-científica (PTC) e a Polícia Judiciária conformam o sistema policial.

A comunicação opera a partir de códigos passíveis de "[...] reagir a um ambiente altamente complexo, sem ter de se adaptar a ele". Os códigos caracterizam-se pela possibilidade de aquisição de biestabilidade, ou seja, pela capacidade de "[...] tomar dois estados [...]" e de se conectarem com ambos os lados de uma distinção. Os códigos, portanto, longe de constituírem um conteúdo comum, são aqui relacionados à possibilidade de "[...] alterar o sentido de ambos os lados da relação codificada [...]" (LUHMANN, 2016, p. 235). Ainda, na análise sistêmica, os programas são definidos como suplementos que viabilizam a operabilidade dos códigos. As decisões da PC-PI podem ser observadas a partir dos programas que orientam seus processos decisórios (legislação, diretrizes internas, prioridades das unidades). Da análise do conteúdo dos IPLS, documento que oficializa as decisões policiais, infere-se que a categoria feminicídio é operacionalizada pela Polícia a partir de cinco documentos: 1. Laudo de Exame Pericial Cadavérico, a cargo do IML; 2. Laudo de Exame Pericial em Local de Crime, a cargo da PTC; 3. Termo de Declarações de testemunhas; 4.Termo de Interrogatório e 5. Relatório final, os três últimos a cargo da Polícia Judiciária.

\subsubsection{As decisões periciais}

No âmbito das decisões periciais, o estudo se propõe a analisar, ainda com base na amostra, os laudos Cadavérico e Local de Crime, constantes em todos os IPLS pesquisados.

\subsection{Laudo de exame pericial cadavérico}

No IML, o exame do cadáver apresenta formato padrão previsto na Carta de Serviços da Perícia Oficial na área criminal (PIAUÍ, 2016a), que contempla tanto o exame externo do cadáver quanto o exame interno, seguindo roteiro fixo, com quesitos que se repetem em 
todos os casos de assassinatos, independentemente do contexto fático consolidado, entre os quais se destacam: preâmbulo, histórico, conclusão e respostas aos quesitos formulados pelo Delegado. A tarefa supõe a tradução de dados empíricos da realidade em categorias jurídicas, ou seja, o emprego de figuras jurídicas do tipo penal "Homicídio". Vislumbra-se, na prática policial, o apego à objetividade do tipo penal como sendo suficiente e necessário à configuração do delito. Sugere-se inserir a perspectiva de gênero no Laudo de Exame Pericial Cadavérico para que as respostas a elas não mais sejam sumárias, restritas ao "sim", ao "não". A mudança na forma do programa propicia instrumentos de abertura cognitiva ao ambiente, em uma forma de escuta à perspectiva de gênero, que poderia repercutir nas decisões das diferentes organizações que participam do trabalho jurídico-penal.

\subsection{Laudo de exame pericial em local de crime}

Da mesma forma que o Laudo de Exame Cadavérico, o local de crime vem regulamentado no CPP, especialmente no art.169. O exame do local de crime também segue formato padrão previsto na Carta de Serviços da Perícia, com quesitos que se alteram muito pouco nos casos de assassinatos, a depender do contexto fático e do delegado requisitante, bloqueando a cognição dos cenários que caracterizam o feminicídio, sobretudo o termo "condição do sexo feminino".

A partir da análise documental dos procedimentos selecionados nesta pesquisa, podem ser avançadas considerações sobre a prova pericial. Alguns dos laudos periciais que instruem os procedimentos explicitam ações de domínio e apropriação do corpo feminino pela força (SEGATO, 2010, p. 21) - vítima se protege dos golpes; relação de verticalidade - agressor em plano superior à vítima e expressividade da violência - golpes sucessivos e profundos, mesmo depois do estado de inércia da vítima (SEGATO, 2010, p. 44, grifo nosso):

[...] A presença de lesões de defesa no seu antebraço e braço, indicam a tentativa da vítima de se proteger dos golpes sofridos [...] lesões pérfuro-incisas profundas [...] mesmo inerte e já caída, no piso cerâmico, a vítima continuou a sofrer agressões, sendo contabilizados pelo menos 06 (seis) golpes [...] cujo agente agressor estava posicionado em plano superior à vítima, desferindo golpes de cima para baixo.

\subsubsection{As decisões da polícia judiciária}

Outro âmbito de análise se refere às decisões da polícia judiciária em relação à investigação policial realizada por meio do inquérito policial. Na divisão do trabalho policial, os delegados de polícia conduzem discricionariamente as investigações policiais. Sob o enfoque sistêmico, suas decisões devem ajustar-se às premissas decisórias na forma dos programas condicionais e finalísticos estabelecidos para a atuação da organização Polícia Civil. Foram analisados Autos de Prisão em Flagrante Delito, requisições periciais, termos de depoimentos e de declarações, interrogatório e relatório. 
Os Termos de depoimento e de declaração tomam por base a terceira pessoa do singular, é dizer, o delegado assume o papel de observador e não documenta o discurso originário verbal. Pode-se inferir, sugere Nascimento (2007, p. 72), haver uma espécie de confisco da narrativa original, transformando-a em discurso traduzido de forma indireta no momento da oitiva, interpretado e ditado pelo delegado ao escrivão que o reduz a escrito.

Todas as peças dos inquéritos policiais, que envolvem falas provenientes de terceiros, adotam o conectivo "que" na passagem do discurso oral ao escrito, fazendo que o discurso perca a pessoalidade. Nascimento $(2007)^{3}$, em seu estudo, valeu-se da pesquisa desenvolvida por Jönsson \& Linell, em que foram analisados interrogatórios escritos e confrontados com suas versões orais. Assim:

[...] o relatório escrito do policial é quase três vezes menor que a transcrição do diálogo estabelecido entre esse e o suspeito, quanto ao fato criminoso, [...]. Além disso, os turnos conversacionais produzidos pelo suspeito possuem mais interrupções e incompletudes, utilizando mais frequentemente de estruturas coordenadas, por meio do conector and, enquanto o policial produz orações subordinadas utilizando conectores como when, and, that, who, which (NASCIMENTO, 2007, p. 74).

As análises realizadas em relação ao discurso policial revelam-se úteis para o objeto deste artigo. De igual modo, pode-se identificar, a partir de fragmento de um interrogatório coletado nos autos de um dos inquéritos policiais componentes da amostra, a mesma metodologia de apropriação do discurso do autor pela polícia, sic:

[...] imaginando que não havia munição, [...] apontou a arma em direção a cabeça de Maria [...] e disparou; QUE a irmã do interrogado que estava ao lado de Maria [...] saiu correndo e chorando e o interrogado afirma que ainda pegou em Maria [...] e a chamou, sendo que imaginou que a mesma havia morrido, saiu em direção o quintal e enterrou a arma, pegou a bicicleta de seu pai e fugiu pela frente da casa [...] (PIAUÍ, 2016b, online).

As formas assumidas pelos discursos recorrentes nos relatórios finais sugerem que a polícia mantém os discursos formalizados, estilizados com citações de depoimentos e interrogatórios, utilizando-se de grifos em negrito ou sublinhado para enfatizar passagens dos discursos. No campo da materialidade, nota-se esforço policial para apontar as inferências desenvolvidas ao longo da investigação. Porém, remete a suposto afastamento do delegado em relação aos fatos.

Dada a importância do recorte empírico para os objetivos da pesquisa, foram considerados recortes pontuais nos 27 IPLS selecionados. A pesquisa apurou que, dos 27 casos analisados, 22 se deram em ambiente exclusivamente interno, correspondendo a 81,48\%, sendo 19 na residência da vítima ou 70,37\% e 3 casos na residência do autor ou 11,11\%. Um deles ocorreu em local interno e externo (3,70\%) e o restante - três deles $(14,82 \%)$ em ambiente externo. Dos 19 casos ocorridos no interior da casa da vítima, 11 foram por arma branca, 5 por arma de fogo e 3 por asfixia.

No tocante ao vínculo da vítima com o autor do fato, apurou-se que 20 delas $(74 \%$ do total da amostra) foram assassinadas em suas casas por homens com quem mantinham ou haviam mantido relações de confiança. $\mathrm{O}$ dado revela possível dificuldade de defesa em 
razão dessas relações. A fim de se buscar mais inferências úteis para a análise do feminicídio, o estudo valeu-se de outros dados para cotejo do contexto fático dos assassinatos na perspectiva de gênero: causa da morte e inferências motivacionais.

\section{Tabela 1 - Causa mortis e motivações}

\begin{tabular}{l} 
Causa mortis \\
\hline Choque hipovolêmico - ação pérfuro \\
contundente - 3 projéteis. \\
Choque hipovolêmico hemorrágico \\
- gravidez de 28 a 34 semanas - 29 \\
perfurações.
\end{tabular}

Edema encefálico difuso.

(1)

"[...] demonstra a intensa raiva que o investigado contra ela nutria [...] alvejou-a quando chegou e quando saiu, atingindo-a em diversas regiões do corpo [...], provocando intenso e desnecessário sofrimento [...] o meio cruel está visivelmente caracterizado sofrimento lento, duradouro imposto à vítima, foi matando aos poucos, deu um tiro na cabeça $[\ldots] "$.

"[...] lhe considera como sobrinha [...] deu uma martelada na cabeça de (vítima) [...] tinha conhecimento que a vítima estava grávida [...] nunca manteve relações sexuais com (vítima) [...]".

"[...] depois que usaram drogas e que estupraram as meninas, (maior) passou a espancar as meninas [...] depois as jogou num barranco [...] elas ficaram muito machucadas [...] (maior) disse que era pra matar [...] como não tinham morrido, os dois passaram a jogar pedras nas cabeças das duas, mas elas continuaram vivas [...] que não tinham nenhum homem com elas [...]".

Choque séptico consequente a fasceíte necrotizante devido ao politraumatismo. Meio cruel. Laudo preliminar - Estupro: "[...] laceração da região perianal e vulvar ensanguentada [...] laceração do intróito vaginal superior e inferior $[\ldots]$ sangramento vaginal abundante [...]".

Lesão por arma de fogo no peito esquerdo. Traumatismo do coração. Tiro a queima roupa.

Não consta laudo.

Não consta laudo.
Foragido. Fala da vítima antes de vir a óbito sobre a ação do autor: "[...] eu vou é fazer tudo com você [...] começou a agredir a declarante com socos, tapas, chutes, ao tempo em que tirava a bermuda da declarante e peças íntimas [...] não chame pelo meu nome senão eu te mato [...] abusou da declarante a força mantendo [...] relação sexual de todas as formas, vaginal, anal, de todo jeito [...] além de bater [...] também mordia o seu corpo, e lhe xingava de "vagabunda", "rapariga" e outros nomes [...]".

"[...] puxou a arma da cintura, ainda segurando a vítima pelos cabelos, efetuou um disparo [...] o relacionamento era conturbado, sendo que o mesmo já havia lesionado (vítima) [...] estavam separados e (vítima) estava tendo um relacionamento [...]".

Invocou o direito a falar em juízo.

"[...] sempre era agredida tanto moralmente como fisicamente pelo seu esposo [...]".

Vítima iria mudar para Goiânia e "[...] já havia comprado a passagem [...] autor havia dito que ela não iria viajar, sendo que nunca aceitou o término do relacionamento e já teria a agredido em outro momento".

Choque hemorrágico hipovolêmico Consta que o autor que tinha depressão, iria ser transferido para - projétil de arma de fogo. Após, Suioutra cidade e a vítima não o acompanharia. O namoro seria instável.

cídio do autor. 


\begin{tabular}{|c|c|}
\hline $\begin{array}{l}\text { Hipertensão intracraniana por edema } \\
\text { cerebral - produzido por arma de fogo. }\end{array}$ & $\begin{array}{l}\text { "O autor aduz que foi testar a arma, a título de 'brincadeira'. [...] ao } \\
\text { cruzar }[\ldots . .] \text { com a vítima na sala }[\ldots] \text { brincou dizendo: 'olha aí vê se } \\
\text { presta' }[. . .] \text { momento em que apontou a arma em direção a cabeça } \\
{[\ldots . .] \text { da vítima }[\ldots . .] \text { e disparou". }}\end{array}$ \\
\hline $\begin{array}{l}\text { Choque hemorrágico hipovolêmico. } \\
\text { Lesões provocadas por meio cruel, } \\
\text { demonstrando que a vítima demorou } \\
\text { a morrer. }\end{array}$ & $\begin{array}{l}\text { Meio insidioso, com múltiplos ferimentos por projéteis de arma de } \\
\text { fogo disparados a curta distância sem possibilitar quaisquer chances } \\
\text { de defesa. }\end{array}$ \\
\hline Não consta laudo. & \begin{tabular}{|l} 
"[...] com um facão na mão e desferiu vários golpes, com muita raiva \\
e desfigurou a vítima. Tal cena aconteceu na frente do sobrinho [...]".
\end{tabular} \\
\hline $\begin{array}{l}\text { Edema cerebral em decorrência de } \\
\text { hemorragia intracraniana. Meio cruel. }\end{array}$ & $\begin{array}{l}\text { "[...] golpeou-a na cabeça com a intenção de matar [...] afirma que } \\
\text { deu duas pauladas na cabeça dela e se não a matasse ela faria uma } \\
\text { macumba para o interrogado". }\end{array}$ \\
\hline $\begin{array}{l}\text { Lesão torácica. } 29 \text { perfurações pelo } \\
\text { corpo. Morte causada por meio cruel. } \\
\text { Sofrimento físico. Vítima dormia. } \\
\text { Vestia apenas calcinha e as vísceras } \\
\text { estavam expostas. }\end{array}$ & $\begin{array}{l}\text { "O autor fechou a porta do quarto aonde dormiam a filha e o en- } \\
\text { teado com uma corda. [...] Os filhos ouviram gritos, quebraram a } \\
\text { corda e ao chegarem no quarto da mãe, viram o autor em cima da } \\
\text { vítima desferindo golpes de faca. [..] ele demonstrava ter prazer no } \\
\text { momento da agressão". }\end{array}$ \\
\hline Não consta. & $\begin{array}{l}\text { "O pai era contrário à reconciliação da filha e já havia dito a mes- } \\
\text { ma que a mataria caso voltasse com (genro) [...] o acusado agiu de } \\
\text { maneira fria e covarde ao desferir as facadas nas vítimas, posto que } \\
\text { impossibilitou totalmente a defesa das mesmas [...] por ser contrário } \\
\text { ao relacionamento." }\end{array}$ \\
\hline Não consta laudo. & $\begin{array}{l}\text { Recognição Visuográfica: “[...] os envolvidos já estavam separados, } \\
\text { porém residiam na mesma residência e inclusive dormiam em quartos } \\
\text { separados, porém o autor não aceitava a separação [...]”. }\end{array}$ \\
\hline $\begin{array}{l}\text { Traumatismo cranianoencefálico } \\
\text { raquimedular por agressão física, es- } \\
\text { pancamento. }\end{array}$ & $\begin{array}{l}\text { "Consta que era violentada fisicamente, estuprada constantemente, } \\
\text { forçada a usar drogas e abusada sexualmente pelo autor. [...] Hema- } \\
\text { tomas no corpo, manchas roxas, bico do peito cortado à dentadas, } \\
\text { genitália inchada e roxa, não conseguia usar calcinha; certa vez em } \\
\text { sua vagina foi inserida uma moeda, tendo sido internada. O autor } \\
\text { ameaçava de morte caso resolvesse se separar. [...]". }\end{array}$ \\
\hline $\begin{array}{l}\text { Choque hemorrágico hipovolêmico. } \\
\text { Corpo arrastado. }\end{array}$ & $\begin{array}{l}\text { "[...] se apossou de um facão que estava na sua casa e não lembra } \\
\text { o que fez depois [...]". }\end{array}$ \\
\hline $\begin{array}{l}\text { Choque hipovolêmico - ação pérfuro } \\
\text { contundente - arma de fogo. Meio } \\
\text { insidioso, com múltiplos ferimentos. } \\
\text { Disparos a curta distância. }\end{array}$ & $\begin{array}{l}\text { "Histórico de violências anteriores narrado pela mãe da vítima. [...] } \\
\text { Autor chama vítima que estava trancada em um quarto, dizendo: } \\
\text { '[...] eu não vou fazer mal a você’ [...] Não aceitava a separação. } \\
\text { Efetuou os disparos na casa da mãe da vítima. Atirou na frente do } \\
\text { filho de } 6 \text { anos". }\end{array}$ \\
\hline $\begin{array}{l}\text { Perfuração torácica - hemopericárdio } \\
\text { - tamponamento cardíaco - choque } \\
\text { cardiogênico - meio insidioso. }\end{array}$ & $\begin{array}{l}\text { "Consta que o autor havia mantido relações sexuais com a vítima, e } \\
\text { esta teria furado os pneus da bicicleta do autor. O autor menciona } \\
\text { que [...] tirou a faca do cós e foi em direção a (vítima) que tropeçou } \\
\text { e caiu, e foi nesse momento que [...] desferiu uma facada entre os } \\
\text { seios de (vítima)". }\end{array}$ \\
\hline
\end{tabular}




\begin{tabular}{|c|c|}
\hline Hemorragia torácica. & $\begin{array}{l}\text { Término do relacionamento e a vítima já estava morando com o pai. } \\
\text { Foi pegar pertences na casa aonde residia com o ex-companheiro } \\
\text { e lá foi assassinada. }\end{array}$ \\
\hline $\begin{array}{l}\text { Choque hipovolêmico hemorrágico - } 9 \\
\text { perfurações por arma branca. }\end{array}$ & $\begin{array}{l}\text { Consta que o irmão da vítima teria trancado autor e vítima em casa } \\
\text { dando uma cópia da chave para o autor para evitar que a vítima } \\
\text { saísse porque havia bebido muito e para não ser falatório na cidade. }\end{array}$ \\
\hline $\begin{array}{l}\text { Asfixia por estrangulamento - } \\
\text { constricção cervical. }\end{array}$ & $\begin{array}{l}\text { Consta que após discussão com a vítima, teria lhe dado uma rasteira } \\
\text { e derrubado ao chão, passando a esganá-la. Alega que "[...] foi um } \\
\text { momento de raiva [...]". Consta relatos de violências anteriores } \\
\text { com prisão. }\end{array}$ \\
\hline $\begin{array}{l}\text { Asfixia devido a esganadura - ação } \\
\text { mecânica. }\end{array}$ & Nega a autoria. \\
\hline $\begin{array}{l}\text { Choque hipovolêmico decorrente de } \\
\text { ação pérfuro-cortante. }\end{array}$ & $\begin{array}{l}\text { "[...] Que o interrogado ao observar a lixeira da casa de (vítima) } \\
\text { percebeu que estava cheia de camisinhas usadas (umas } 07 \text { ou } 08 \\
\text { camisinhas), oportunidade em que se revoltou e voltou para o quarto } \\
\text { e continuou bebendo cervejas no quarto com (vítima); Que pouco } \\
\text { tempo antes [...] havia mantido relações sexuais com (vítima); [...] } \\
\text { Que quando (vítima) deu as costas para o interrogado, ainda dei- } \\
\text { tada, o interrogado a indagou se esta estava traindo o interrogado, } \\
\text { momento em que (vítima) afirmou que não; Que após a resposta de } \\
\text { (vítima), o interrogado cravou a faca nas suas costas, oportunidade } \\
\text { em que esta rolou na cama e caiu no chão, aos pés da cama; [...]". }\end{array}$ \\
\hline $\begin{array}{l}\text { Choque hipovolêmico, hipertensão } \\
\text { arterial, hemorragia interna - } \\
9 \text { perfurações. }\end{array}$ & Consta argumento de defesa e depressão do autor. \\
\hline Força física: asfixia/Estrangulamento. & $\begin{array}{l}\text { "[...] passou a esganá-la com as mãos, apertando principalmente na } \\
\text { região da laringe; Que a vítima demorou a morrer [...] alega que foi } \\
\text { um momento de raiva [...]". }\end{array}$ \\
\hline $\begin{array}{l}\text { Hemorragia aguda com sinais de } \\
\text { crueldade. }\end{array}$ & $\begin{array}{l}\text { Violências anteriores narradas pela vítima. } \\
\text { Suicídio do autor com arma de fogo. } \\
\text { Término do relacionamento. } \\
\text { A vítima teria indagado ao autor: "tu tem coragem de fazer isso comigo?" }\end{array}$ \\
\hline
\end{tabular}

Fonte: (PIAUI, 2016b).

Ao se confrontar os discursos policiais selecionados, depreende-se a articulação entre as decisões das organizações policiais - perícia e polícia judiciária, que orientam a conclusão que é levada ao relatório final. A forma de comunicação da polícia sugere possível fechamento cognitivo da organização policial às peculiaridades que envolvem o feminicídio e que o diferenciam das outras mortes qualificadas. Os textos propiciam material relevante para a análise. Relatos como "[...] provocando intenso e desnecessário sofrimento [...], com evidente instinto de maldade, objetivando impor à vítima um sofrimento desnecessário [...]", narrativa de caso em que o padrasto assassina a enteada ou então "[...] depois as jogou num barranco [...] e como não haviam morrido [...] passaram a jogar pedras nas cabeças das duas 
[...] que não tinham nenhum homem com elas [...]" (PIAUÍ, 2016b), são elucidativos, pois se referem a casos envolvendo quatro meninas violadas sexualmente e vítimas de feminicídio, modalidade tentada (um consumado), praticados por 4 adolescentes e um homem que não mantinham relações interpessoais com elas.

Os relatos interpelam especialistas sobre os significados da prática. As narrativas podem revelar, conforme Segato, a marca que excede o racional, podendo dizer-se “[...] que se trata de una violencia instrumental orientada hacia un valor, esto es, la reparación o adquisición de un prestigio." (SEGATO, 2010, p. 42-44). Desvela-se linguagem peculiar que enfatiza emprego de força que excede racionalmente o esforço necessário para a eliminação de uma pessoa. Assume-se a forma de gesto simbólico de imposição de castigo pela violação do prestígio pessoal do autor do fato, no primeiro caso, e aquisição de um prestígio no segundo caso. Relatos de causa mortis relacionados ao emprego da força física nos casos de asfixia por estrangulamento (esganadura) expõem a precariedade da vida das vítimas. No léxico proposto por Butler, vidas que podem ser perdidas, destruídas ou sistematicamente negligenciadas até a morte, "[...] o fato de que a morte é certa, [...] de que a vida de alguém está sempre, de alguma forma, nas mãos do outro.” (BUTLER, 2016, p. 31).

\section{PROGRAMA OPERACIONAL NA PERSPECTIVA DE GÊNERO}

A estilização dos documentos analisados vai muito além da mera burocratização das atividades da Polícia Civil. Indicam as rotinas cognitivas que orientam os processos decisórios da polícia. A padronização permite entrever lacunas que dificultam a tradução das perspectivas de gênero na atividade hermenêutica de compreensão dos significados do ato de matar. Após o percurso indicado, sugere-se que a investigação policial supõe a inserção de protocolos de atuação que acoplem a complexidade das violências de gênero ao sistema policial civil, de forma a instituir novas premissas decisórias.

Certamente, a construção de estratégias para enfrentar a violência de gênero depende da produção de mais investigações que permitam a produção de diagnósticos mais precisos (SEGATO, 2010, p. 134). Como forma de superar o déficit investigatório, o Núcleo de Estudo e Pesquisa em Violência de Gênero da SSP/PI elaborou Metodologia Investigatória do Feminicídio, tomando como eixos as Diretrizes Nacionais Feminicídio, a metodologia investigatória do homicídio elaborada pelo Núcleo de Inteligência da SSP/PI, o conteúdo de inquéritos policiais que apuraram feminicídio, o Protocolo de Bogotá e os dados dos sistemas operacionais da Polícia SISBO, SISPROCEP e SIMCVLI. O modelo foi construído a partir de três componentes: fático, jurídico e probatório. Deles resultaram variados protocolos, entre os quais se destaca a Recognição Visuográfica na Perspectiva de Gênero, Dogmática jurídica e Discursos oficiais. A figura 1 ilustra os três componentes da metodologia. 


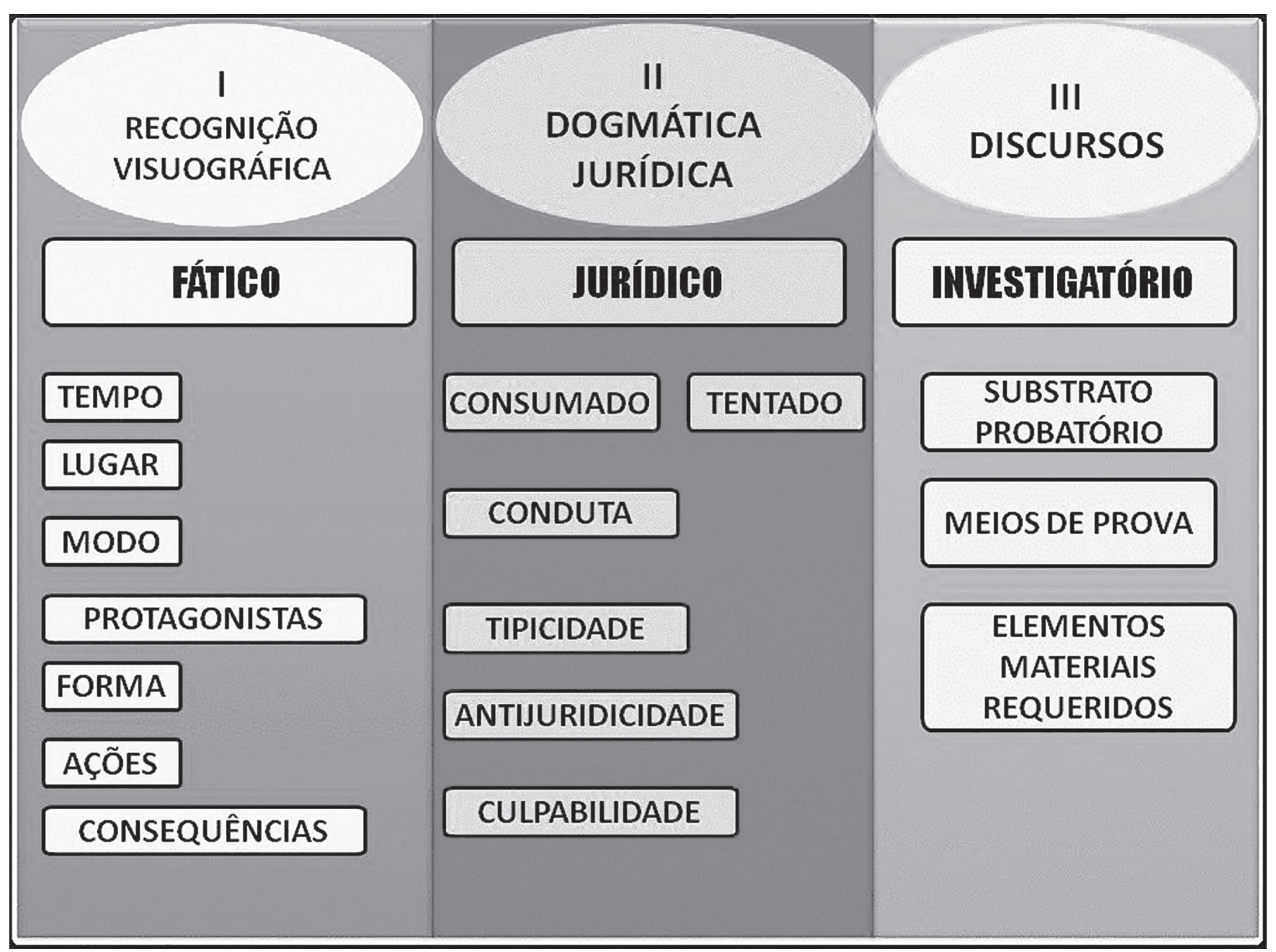

Figura 1 - Metodologia investigatória do Feminicídio Fonte: (PIAUÍ, 2017).

Os componentes apresentam-se como artefatos semânticos que propiciam a abertura cognitiva do sistema policial à complexidade do evento descrito como feminicídio. Cada componente da metodologia proposta sugere a construção de mapa cognitivo orientado pelo gênero, ou seja, o gênero constitui-se em elemento diferenciador da programação, atuando de forma transversal sem que se altere a unidade do sistema.

Em estudo anterior, foram propostas três categorias, tomando por base a mesma amostra desta pesquisa. As categorias foram assim classificadas: teóricas, empíricas e jurídicas, conforme tabela abaixo.

Tabela 2 - Categorias teóricas/Categorias empíricas/Unidades de análise

\begin{tabular}{l|l|l}
\hline \multicolumn{1}{c|}{ Categorias teóricas } & \multicolumn{1}{c|}{ Categorias empíricas } & \multicolumn{1}{c}{ Categorias jurídicas } \\
\hline \multicolumn{1}{c|}{ Dominação } & \multicolumn{1}{c}{ Gênero } & \multicolumn{1}{c}{ Linguagem } \\
\hline $\begin{array}{l}\text { Lógica patriarcal } \\
\text { - Relações de gênero hierárquicas } \\
\text { e desiguais } \\
\text { - Colonização do corpo }\end{array}$ & $\begin{array}{l}\text { Domínio existente } \\
\bullet \text { Sentimento de propriedade } \\
\bullet \text { Controle do corpo }\end{array}$ & $\begin{array}{l}\text { Lógica do espaço doméstico } \\
\bullet \text { Violência doméstica e familiar } \\
\bullet \text { Tortura } \\
\bullet \text { Violação à saúde }\end{array}$ \\
\hline
\end{tabular}




\begin{tabular}{|c|c|c|}
\hline $\begin{array}{l}\text { Lógica do mandato ou tributo } \\
\text { - Territorialização do corpo } \\
\text { - Consumo do corpo }\end{array}$ & $\begin{array}{l}\text { Exibição do domínio } \\
\text { - Misoginia } \\
\text { - Sentimento de propriedade } \\
\text { - Discriminação } \\
\text { - Repulsa ao gênero feminino }\end{array}$ & $\begin{array}{l}\text { 2. Lógica do espaço público } \\
\text { - Violência na comunidade } \\
\text { - Menosprezo ou discriminação } \\
\text { à condição de mulher }\end{array}$ \\
\hline
\end{tabular}

Fonte: (VILLA, 2017).

O Componente fático alia circunstâncias de tempo, modo, lugar, protagonistas, forma, ações e consequências na perspectiva de gênero e será construído a partir da aplicação da Recognição Visuográfica pela polícia judiciária no momento em que se deslocar ao local do crime.

O Componente Jurídico - Dogmática Jurídica - reúne instrumentos de Direito Interno e Internacional que versem sobre violência na perspectiva de gênero, além de jurisprudências e literatura jurídica e não jurídica. O Protocolo tem por objetivo auxiliar o delegado na tipificação do feminicídio a partir de um horizonte cognitivo ampliado por artefatos semânticos que elucidem a variante gênero como dado relevante na construção jurídica realizada pela organização PC-PI.

Por fim, a metodologia contempla o Componente Probatório, consistente nos discursos oficiais e não oficiais que integram o IPL. São oficiais os discursos emanados diretamente da polícia: laudos periciais, recognição visuográfica e registros policiais anteriores em boletins de ocorrência, relatórios e ordem de missão policial. Os não oficiais são oriundos da vítima, das testemunhas, dos informantes e do autor do fato, tomados oficialmente pela polícia nos seus processos decisórios para consubstanciarem atos de investigação documentados nos autos do IPL.

O componente probatório ensejou alterações no padrão das requisições periciais para inserir a perspectiva de gênero nas quesitações. A metodologia representa um avanço no campo da investigação policial, caracterizando-se como mudança de paradigma que possibilitará uma reprogramação das práticas cognitivas operacionais da polícia na condução dos feminicídios.

Resta agora o desafio de desconstruir rotinas cognitivas que possam bloquear a nova programação. Em términos sistêmicos, trata-se da adaptação ao novo ambiente, mantendo sua característica de biestabilidade, fazendo "[...] que o sistema, totalmente determinado, possa reagir a um ambiente altamente complexo, sem ter de se adaptar a ele [...]" (LUHMANN, 2016, p. 235). A biestabilidade permite aberturas no sistema a fim de conferir inteligibilidade à perspectiva de gênero na forma como se comunica a Polícia Civil. No âmbito do sistema, o que se vai levar em consideração é a ideia de pertencimento ou não pertencimento, porque “[...] Para fins de programação, o caráter unívoco do código, que se encontra apenas em seu estado binário, tem de se abrir. Os valores do código devem ser interpretados como possibilidades; ou em outros termos, como um meio que pode aceitar formas diversas." (LUHMANN, 2016, p. 257).

Muitas inferências ainda poderão ser construídas a partir dos mapas e das tabelas. Mais que respostas definitivas, a pesquisa sugere questionamentos: Como a polícia civil observa a categoria feminicídio? Pode-se inferir que existem limites cognitivos que bloqueiam a capitulação do feminicídio no sistema policial? O sistema operativo da polícia pode abrir-se cognitivamente à complexidade das violências de gênero? 


\title{
7 CONSIDERAÇÕES FINAIS
}

Embora sejam identificadas nos laudos depoimentos, declarações e interrogatórios, nota-se que o sistema Polícia Civil observa a prática do feminicídio conforme programas padronizados e rotinas cognitivas estabilizadas para a investigação dos crimes contra a pessoa, de forma generalizada.

A construção da Metodologia Investigatória do Feminicídio apresenta-se como artefato semântico que pretende instituir instrumentos que propiciem a abertura cognitiva do sistema policial ao entorno. Propõe-se como mecanismo apto a reprogramar a investigação policial, com protocolos sensíveis ao paradigma de gênero. A metodologia potencializa o ingresso de inferências relevantes para as decisões policiais e possibilita contemplar a variável gênero como categoria construída culturalmente, que remete a posições marcadas por relações hierárquicas, de controle, colonização do corpo ou de propriedade.

\section{THE MAP OF FEMINICIDE IN THE POLICE OF PIAUÍ: A SYSTEMIC- ORGANIZACIONAL APPROACH}

\begin{abstract}
The study is in the field of violence against women, regarding the murder of women on the basis of gender. Based on information extracted from the official databases of the Civil Police of Piaui and on the analysis of police inquiries that investigated feminicide, a map of such crime in the State of Piauí is drawn up, based on the same categories elected by Waiselfisz in the Map of Violence 2015 - Homicide of Women in Brazil, as a paradigm of data analysis. The research is pioneering because it is the first map drawn up after the entry into force of Law no. 13.104/15, which instituted feminicide as a crime in Brazil. The study detects gaps in the criminal norm that hinder the application of the aggravating circumstance of feminicide, understood as the killing of a woman "for reasons related to the fact that she belongs to the female sex." To understand how this gap has been overcome in the context of police organizational culture, the study analyzes the content of 27 of a total of 50 police surveys of consummated feminicides that took place from 03.03.15 to 30.08.16. The following criteria were chosen as the object of analysis: expert reports, terms of hearings, arrest warrants in flagrante delicto, interrogation briefs and reports. Next, the research, driven by discourse analysis and organizational approach, maps empirical categories, so as to go into the police routine and see how organizations observe feminicide and how they communicate (decide).
\end{abstract}

Keywords: Language of Feminicide. Systems. Research methodology. Police organization. 


\section{EL MAPA DEL FEMINICIDIO EN LA POLICÍA CIVIL DEL PIAUÍ: UN ANÁLISIS ORGANIZACIONAL-SISTÉMICA}

\section{RESUMEN}

El estudio se inserte en el tema de la violencia contra la mujer, en la perspectiva del asesinato de mujeres por razones de género. A partir de informaciones extraídas de bancos de datos oficiales de la Policía Civil del Piauí y análisis de investigaciones policiales que apuraron feminicidio, se elabora un mapa del feminicidio en el Estado de Piauí, tomándose por base las mismas categorías escogidas por Waiselfisz, en el Mapa de la Violencia 2015 - Homicidio de Mujeres en el Brasil como paradigma de análisis de datos. La investigación es pionera porque constituye el primer mapa después de la vigencia de la Ley n. 13.104/15, que instituyó el feminicidio en Brasil. El estudio detecta omisiones en el tipo penal que dificultan la aplicación de la calificadora feminicidio sobre lo que se podría entender por matar una mujer "por razones de la condición del sexo femenino". Para comprender como esa omisión viene siendo superada en el ámbito de la cultura organizacional policial, el estudio analiza el contenido de 27 de un total de 50 investigaciones policiales de feminicidios consumados producidos en el periodo de 10.03.2015 hasta 30.08.2016. Fueron elegidos como objeto de análisis: laudos periciales, términos de audiencias, actos de prisión en flagrante, interrogatorios y informes. Enseguida, la investigación, orientada por el análisis del discurso y por el abordaje organizacional, mapea categorías empíricas en ellos presentes para adentrar en la rutina policial y verificar como las organizaciones observan el feminicidio y de qué modo se comunican (deciden).

Palabras-clave: Lenguaje del feminicidio. Sistemas. Metodología investigadora. Organizaciones policiales.

1 "Por lo tanto, es posible afirmar que el sistema no se reproduce automáticamente ni está prederteminado a reproducirse como consecuencia de una ley natural, sino que lo hace mediante un repetitivo ciclo de violencia, en su esfuerzo por la restauración constante de la economia simbólica que estructuralmente organiza la relación entre los estatus relativos de poder y subordinación representados por el hombre y la mujer como iconos de las posiciones masculina y femenina así como de todas sus transposiciones en el espacio jerárquico global." (SEGATO, 2010, p. 144).

2 "As rotinas estabelecidas incluem formas, regras, procedimentos, estratégias e tecnologias a partir das quais as organizações operam. Estas contemplam também o conjunto de crenças, valores e códigos sociais que sustentam ou não as rotinas organizacionais." (MACHADO, 2014, p. 34).

3 A fim de ilustrar seu pensamento, a autora traz uma passagem do estudo de Jönsson \& Linell que revela como a linguagem oral é apropriada pelo discurso policial no momento da escrita: $\mathrm{O}$ relato estabelece outra descrição de causalidades implicadas na história contada. O suspeito conta sua história de como os dois, mais ou menos de repente e não intencionalmente, parece, acabaram em uma situação que veio a ter alguma consequência infeliz para eles. Por alguma razão, eles foram as vítimas das circunstâncias; alguma coisa aconteceu a eles. Ao contrário, o relatório do policial conta uma história de ações racionais e controladas baseadas em decisões claras: 'então eles estabeleceram que $[\ldots]$, eles decidiram tentar apropriar [...] etc'. (NASCIMENTO, 2007, p. 74). 


\section{REFERÊNCIAS}

AGUIAR, João Marcelo Brasileiro de. Análise Estatística dos crimes violentos letais intencionais em Teresina, nos anos 2014 e 2015. 2016. Trabalho de Conclusão de Curso (Especialização) - Universidade Federal do Piauí, 2016.

BACHELARD, Gastón. La formation de l'esprit scientifique. Paris: Vrim, 1938.

BRASIL. Código Penal. Código de Processo Penal. Constituição Federal. Legislação penal e processual penal. 17. ed. São Paulo: Revista dos Tribunais, 2015b.

. Ministério das Mulheres, da Igualdade Racial e dos Direitos Humanos. Diretrizes nacionais feminicídio: investigar, processar e julgar com perspectiva de gênero as mortes violentas de mulheres. Brasília: [s.n.], 2016.

. Lei $\mathrm{n}^{\circ} 13.104$, de 9 de março de 2015. Altera o art. 121 do Decreto-Lei no 2.848, de 7 de dezembro de 1940 - Código Penal, para prever o feminicídio como circunstância qualificadora do crime de homicídio, e o art. $1^{\circ}$ da Lei no 8.072, de 25 de julho de 1990, para incluir o feminicídio no rol dos crimes hediondos. Presidência da República, Brasília, DF, 2015a. Disponível em: <http://www.planalto.gov.br/ccivil_03/_Ato2015-2018/2015/ lei/L13104.htm > . Acesso em: 1 maio 2017.

BUTLER, Judith; LACLAU, Ernesto; ZIZEK, Slavoj. Contingência, hegemonia, universalidade: diálogos contemporâneos en la izquierda. Buenos Aires: Fondo de Cultura Economica de Argentina, 2000.

BUTLER, Judith. Quadros de guerra: quando a vida é passível de luto? Rio de Janeiro: Civilização Brasileira, 2015.

. Quadros de guerra: quando a vida é passível de luto? 2. ed. Rio de Janeiro: Civilização Brasileira, 2016.

FOUCAULT, Michel. A ordem do discurso. 23. ed. São Paulo: Edições Loyola, 2013.

LAGE, Lana; NADER, Maria Beatriz. Violência contra a mulher: da legitimação à condenação social: nova história das mulheres no Brasil. São Paulo: Contexto, 2013.

LUHMANN, Niklas. O direito da sociedade. São Paulo: Martins Fontes, 2016.

MACHADO, Bruno Amaral. Justiça criminal: diferenciação funcional, interações organizacionais e decisões. São Paulo: Marcial Pons, 2014.

NASCIMENTO, Águeda Bueno do. A retextualização como instrumento de manipulação no discurso jurídico penal. 2007. 183 f. Dissertação (Mestrado em Linguística) - Universidade Federal de Minas Gerais, 2007.

PIAUÍ. Polícia Técnico-científica. Carta de serviços: serviços da perícia oficial prestados no estado do Piauí na área criminal. Teresina: [s.n.], 2016a. 
. Portaria $\mathrm{n}^{\mathrm{0}}$ 064- /GS/2015, de 2 de março de 2015. Diário Oficial do Estado do Piauí, Teresina, PI, n. 41, p. 3, 4 mar. 2015.

. Secretaria de Segurança Pública. Apostila de capacitação: metodologia investigatória na perspectiva de gênero - núcleo de estudo e pesquisa em violência de gênero. Teresina: [s.n.], 2017.

- Secretaria de Segurança Pública. Núcleo de Estudo e pesquisa em Violência de Gênero SSP/PI. Conjunto de 27 inquéritos policiais. Teresina: [s.n.], 2016b.

SÁNCHEZ, Bernardo Feijó. Derecho penal y neurociência: una relación tormentosa? Revista para el Análisis del Derecho, n. 2, abr. 2011. Disponível em: < http://www.indret.com/ pdf/806.pdf>. Acesso em: 1 maio 2017.

SEGATO, Rita Laura. Las estructuras elementales de la violencia: ensayos sobre género entre la antropologia, el psicoanálisis y los derechos humanos. Buenos Aires: Prometeo libros, 2010.

WAISELFISZ, Julio Jacobo. Mapa da violência 2015: homicídio de mulheres no Brasil. 2015. Disponível em:<http://www.mapadaviolencia.org.br>. Acesso em: 1 maio 2017.

VILLA, Eugênia Nogueira do Rêgo Monteiro. Balizas para um procedimento investigatório policial na perspectiva de gênero. Artigo apresentado como requisito para aprovação na disciplina Tendências e desafios do direito processual do Programa de Pós-graduação Stricto Sensu em Direito, nível Doutorado, área de concentração Direito e Políticas Públicas. Teresina: UNICEUB, 2017.

Submetido: 10 jun. 2017

Aprovado: 20 out. 2017 